\title{
Musculoskeletal disorders increases the insomnia severity in nurses
}

Remziye Cici*

Gülay Yilmazel

Hitit University Faculty of Health Sciences, Nursing - Çorum - Çorum - Turkey.
*Corresponding author:

Remziye Cici

E-mail: remziyecici@hotmail.com /

remziyecici@hitit.edu.tr

Received: December 3, 2020;

Accepted: February 22, 2021.

\begin{abstract}
Objectives: To determine prevalence of musculoskeletal disorders and the relationship between insomnia severity among nurses working in a training and research hospital. Material and Methods: This descriptive study was carried out with 293 nurses. Cornell musculoskeletal disorders questionnaire for musculoskeletal disorders and insomnia severity index were used to determine the insomnia severity. Results: In our study, the severity of the discomfort was mostly moderate and mild in painful areas. There was a significant difference in terms of gender, educational status, marital status, seniority, types of working, and presence of chronic diseases for musculoskeletal disorders in different body regions $(\mathrm{p}<0.05)$. It was determined that the threshold level of insomnia was significantly higher in those with musculoskeletal disorders in other body regions except the knee and lower leg region $(\mathrm{p}<0.05)$. Conclusion: In our study, it was determined that musculoskeletal disorders were common in the upper body areas and the severity of insomnia was at the threshold level. Neck, right shoulder and right upper arm were risky body areas for insomnia.
\end{abstract}

Keywords: Musculoskeletal Diseases; Nurses; Sleep. 


\section{INTRODUCTION}

Musculoskeletal disorders (MSD) defined with two components as "muscular system and the skeletal system", which are acute or chronically affecting disorders that triggered by work may impair the function of different body parts depending on the workplace and the employee ${ }^{1}$.

Musculoskeletal disorders are one of the most important challenges of occupational health in today's world and are present in many jobs ${ }^{2,3}$.

Stress experienced in the work environment with many triggering factors such as movements that force the posture, traumas caused by repetitive movements, intense physical workload, disproportionate or improper use of body parts creates a serious load on the musculoskeletal system ${ }^{4}$. Workrelated MSD have been reported to be highly prevalent in developing and developed countries ${ }^{5-7}$.

Although MSD are high in the general population, it is seen that especially those working in the field of medical care face these problems more ${ }^{8,9}$. Assessment of the incidence of MSD in healthcare providers is seriously addressed in many countries $^{10}$. Among those who direct contact with patients, especially nurses among the health professionals are under the risk of $\mathrm{MSD}^{11,12}$. It has been reported that the prevalence of MSD in nurses worldwide is between $40-90 \%{ }^{13}$.

Musculoskeletal disorders are associated with improper body mechanics ${ }^{14}$ as well as poor sleep quality in health workers ${ }^{15}$. Sleep problems occur as a result of irregular working hours that do not comply with routine sleep-wake hours and stress in the work environment ${ }^{16}$. In a study conducted with hospital staff ( $58 \%$ of 3,593 participants were nurses), $57 \%$ of the participants were reported to have poor sleep ${ }^{15}$. Sleep problems may lead to decreased work performance and attention, chronic fatigue, mood disorders, gastrointestinal system problems, increased risk of hypertension and cardiovascular disease ${ }^{16}$, and pain sensitivity ${ }^{15}$. However, the link between pain and insomnia may not be determined exactly ${ }^{15}$.

The aim of study was to determine prevalence of the musculoskeletal disorders and the relationship between insomnia severity among nurses working in a training and research hospital.

\section{MATERIAL AND METHODS}

This descriptive study was carried out between OctoberNovember 2020 in a city located Black Sea Region of Turkey. The population of study was consisted of 435 nurses working in an education and research hospital. For the study, all surgical and internal departments were chosen in hospital and 293 nurses were included with the random sampling method. The inclusion criteria of the participants in the study were as follows: those aged 20 years and over, those without diagnosed any musculoskeletal and mental disorders. Nurses were visited by researchers in their clinics and data were collected via a questionnaire form. In the questionnaire form, socio-demographic characteristics of the nurses were questioned. Age, gender, graduation, marital status, seniority, types of working and clinic, chronic condition were socio-demographic variables. Also to evaluate MSD "Cornell musculoskeletal discomfort questionnaire" and to determine the severity of insomnia "insomnia severity index" were used. Survey forms took an average of 30 minutes to respond.

\section{Cornell musculoskeletal discomfort questionnaire}

The Cornell musculoskeletal discomfort questionnaire (CMDQ) is a data collection tool developed in the Human Factors and Ergonomics Laboratory at Cornell University for the assessment of musculoskeletal symptoms among the Englishspeaking workforce ${ }^{17}$. It determines the frequency and severity of pain or discomfort and assesses its impact on business performance in 11 different body regions (neck, shoulder, back, upper arm, waist, forearm, wrist, hip, upper leg, knee, and lower leg) during the last week. The frequency of pain or discomfort was rated between never (0) and many times every day (4); severity was rated between mild (1) to very severe (3), and its impact on job performance was rated never obstacle (1) to very obstacle (3).

The questionnaire consisted of right and left subcategories of other extremity sections except neck, back, waist, and hip region. Weighted scores is calculated from the areas of frequency, severity, and work performance for each body region. The weighted score for each body region takes a value between 0 and 90 . The increased scores shows that effect on pain frequency, severity, and job performance ${ }^{17}$. The Turkish validity and reliability study was conducted by Erdinc et al., in $2011^{18}$ and the Cronbach alpha value was 0.876 for frequency, 0.895 for severity, and 0.875 for work performance.

In this study right shoulder, right upper arm, right forearm, and right wrist considered as right upper extremity and left shoulder, left upper arm, left forearm, and left wrist were considered as left upper extremity. Also, right upper leg, right knee, right lower leg were evaluated as lower right extremity and left upper leg, left knee, and lower left leg were considered as lower left extremity. The weighted score is between 0-360 on the right and left upper extremities and 0-270 on the right and left lower extremities.

\section{Insomnia severity index}

This index, which was developed to determine the degree of insomnia symptoms, can be used in normal community screening and clinical evaluation of insomnia. It is a five-point Likert-type scale consisting of seven items. Each item is scored between 0 and 4 , and the total score ranges from 0 to 28 . The scores of $0-7$ indicates clinically insignificant insomnia, 8-14 shows insomnia lower threshold, 15-21 shows clinical insomnia (moderate severity), 22-28 shows clinical insomnia (severe ${ }^{19}$. The Turkish validity and reliability study was conducted by Boysan et al., in $2010^{20}$. The internal consistency coefficient of the scale was found to be $0.79^{20}$.

\section{Ethical consent}

This study was planned in accordance with the Helsinki principles and consent was obtained from the local ethics committee. After giving information about the study, informed consent was obtained from the nurses to participate in the study. 


\section{Statistical analysis}

All data were analyzed via using SPSS 22.0 program. In analysis, percentage, average, independent t-test and chi-square test was used to compare categorical variables. Also, multiple binary logistic regression analyses were used. To predict significant factors for insomnia, odds ratio (OR) and $95 \%$ confidence interval (CI) were calculated. In evaluations, $p<0.05$ value considered as statistically significant.

\section{RESULTS}

In the study group, $66.6 \%$ were aged $\leq 35$ years with the mean age $31.8 \pm 8.4$ years, $77.8 \%$ were women, $83.3 \%$ were university graduates, and $57.7 \%$ were married. The rate of nurses those with $<10$ years in their profession was $55.6 \%$ while $81.6 \%$ were working with shifts and $56.3 \%$ were working in internal clinics.

The average scores of the participants obtained from the Cornell musculoskeletal disorder questionnaire and insomnia severity index were shown in Table 1. Accordingly, the body area where the participants experience the most MSD was the waist.

Musculoskeletal disorder in lower extremities was higher than upper extremities. In addition, there were more MSD on the right side of the body than on the left side. The severity of insomnia among the participants was at the threshold level.

The pain and discomfort experienced by the participants according to their body areas were shown in Table 2. Body areas where the participants had the most pain complaints and had most obstacles in their job were waist, neck, and back. The severity of the discomfort was mostly moderate in painful areas. The areas with the most severe pain were observed to be the neck, back, and waist (Figure 1). According to some characteristics of the participants, the average scores of the Cornell musculoskeletal disorders questionnaire were presented in Table 3.

There was no statistically significant difference between the mean scores of age and BMI with MSD scores $(p>0.05)$. In our

Table 1. The distribution of the scores obtained from the scales.

\begin{tabular}{lcc}
\hline Scales & $\mathbf{X} \pm \mathbf{S S}$ & Minimum-maximum values that can be obtained from the scale \\
\hline Cornell musculoskeletal disorders questionnaire & & $0-90$ \\
Neck & $6,89 \pm 5,32$ & $0-90$ \\
Back & $7,22 \pm 5,60$ & $0-90$ \\
Waist & $7,86 \pm 5,56$ & $0-90$ \\
Hip & $4,57 \pm 4,73$ & $0-360$ \\
Upper extremity & & $0-360$ \\
Right & $18,07 \pm 14,92$ & $0-270$ \\
Left & $15,32 \pm 13,76$ & $0-270$ \\
Lower extremity & & $0-28$ \\
Right & $23,76 \pm 17,90$ & $21,76 \pm 17,99$ \\
Left & $10,92 \pm 5,62$ & \\
Insomnia severity index & & \\
\hline
\end{tabular}

Table 2. Existence of musculoskeletal disorders and obstacle to doing job according to body areas.

\begin{tabular}{|c|c|c|c|c|}
\hline \multirow{2}{*}{ Body areas } & \multicolumn{2}{|c|}{ Musculoskeletal disorder } & \multicolumn{2}{|c|}{ Obstacle status for job } \\
\hline & Had n (\%) & Had not n (\%) & Obstacle n (\%) & Not obstacle n (\%) \\
\hline Neck Shoulder & $198(67,6)$ & $95(32,4)$ & $107(36,6)$ & $186(63,4)$ \\
\hline Right & $166(56,7)$ & $127(43,3)$ & $92(31,4)$ & $201(68,6)$ \\
\hline Left & $137(46,8)$ & $156(53,2)$ & $72(24,6)$ & $221(75,4)$ \\
\hline Back & $198(67,6)$ & $95(32,4)$ & $114(38,9)$ & $179(61,1)$ \\
\hline \multicolumn{5}{|l|}{ Upper arm } \\
\hline Right & $115(39,2)$ & $178(60,8)$ & $50(17,1)$ & $243(82,9)$ \\
\hline Left & $93(31,7)$ & $200(68,3)$ & $37(12,7)$ & $256(87,3)$ \\
\hline Waist Forearm & $214(73,0)$ & $79(27,0)$ & $132(45,1)$ & $161(54,9)$ \\
\hline Right & $90(30,7)$ & $203(69,3)$ & $37(12,6)$ & $256(87,4)$ \\
\hline Left & $71(24,2)$ & $222(75,8)$ & $31(10,6)$ & $262(89,4)$ \\
\hline \multicolumn{5}{|l|}{ Wrist } \\
\hline Right & $93(31,7)$ & $200(68,3)$ & $45(15,4)$ & $248(84,6)$ \\
\hline Left & $79(27,0)$ & $214(73,0)$ & $37(12,7)$ & $256(87,3)$ \\
\hline Hip Upper leg & $121(41,3)$ & $172(58,7)$ & $63(21,5)$ & $230(78,5)$ \\
\hline Right & $137(46,8)$ & $156(53,2)$ & $72(24,6)$ & $221(75,4)$ \\
\hline Left & $124(42,3)$ & $169(57,7)$ & $62(21,1)$ & $231(78,9)$ \\
\hline \multicolumn{5}{|l|}{ Knee } \\
\hline Right & $154(52,6)$ & $139(47,4)$ & $84(28,7)$ & $209(71,3)$ \\
\hline Left & $135(46,1)$ & $158(53,9)$ & $74(25,2)$ & $219(74,8)$ \\
\hline \multicolumn{5}{|l|}{ Lower leg } \\
\hline Right & $160(54,6)$ & $133(45,4)$ & $88(30,0)$ & $205(70,0)$ \\
\hline Left & $148(50,5)$ & $145(49,5)$ & $76(25,9)$ & $217(74,1)$ \\
\hline
\end{tabular}


Musculoskeletal disorders increases the insomnia severity in nurses

Table 3. Scores obtained from the Cornell musculoskeletal disorders questionnaire according to the socio- demographic characteristics of the participants.

\begin{tabular}{|c|c|c|c|c|c|c|c|c|}
\hline Characteristics & Neck & Back & Waist & Hip & $\begin{array}{l}\text { Upper extremity } \\
\text { (R) }\end{array}$ & Upper extremity (L) & Lower extremity (R) & $\begin{array}{l}\text { Lower extremity } \\
\text { (L) }\end{array}$ \\
\hline \multicolumn{9}{|l|}{$\begin{array}{l}\text { Age groups } \\
\text { (year) }\end{array}$} \\
\hline$\leq 35$ & $6,85 \pm 5,28$ & $7,33 \pm 5,53$ & $7,59 \pm 5,29$ & $4,37 \pm 4,59$ & $17,07 \pm 13,18$ & $14,84 \pm 12,49$ & $23,34 \pm 17,22$ & $21,66 \pm 17,63$ \\
\hline$>35$ & $6,96 \pm 5,42$ & $7,00 \pm 5,75$ & $8,38 \pm 6,05$ & $4,97 \pm 5,00$ & $20,09 \pm 17,82$ & $16,27 \pm 16,01$ & $24,58 \pm 19,26$ & $21,97 \pm 18,77$ \\
\hline$p$ & 0,927 & 0,450 & 0,382 & 0,313 & 0,606 & 0,850 & 0,974 & 0,767 \\
\hline \multicolumn{9}{|l|}{ Gender } \\
\hline Female & $7,31 \pm 5,49$ & $7,45 \pm 5,66$ & $8,15 \pm 5,55$ & $4,90 \pm 4,98$ & $19,11 \pm 15,85$ & $15,94 \pm 14,74$ & $24,88 \pm 18,55$ & $22,57 \pm 18,68$ \\
\hline male & $5,42 \pm 4,37$ & $6,40 \pm 5,33$ & $6,83 \pm 5,52$ & $3,42 \pm 3,54$ & $14,40 \pm 10,27$ & $13,13 \pm 9,32$ & $19,81 \pm 14,87$ & $18,94 \pm 15,09$ \\
\hline$p$ & 0,016 & 0,159 & 0,068 & 0,047 & 0,039 & 0,430 & 0,071 & 0,404 \\
\hline \multicolumn{9}{|l|}{ Graduation } \\
\hline High school & $6,93 \pm 5,25$ & $6,35 \pm 5,14$ & $7,76 \pm 5,43$ & $4,34 \pm 4,22$ & $13,95 \pm 10,84$ & $12,07 \pm 9,59$ & $22,45 \pm 16,25$ & \\
\hline University & $6,88 \pm 5,34$ & $7,39 \pm 5,68$ & $7,87 \pm 5,59$ & $4,61 \pm 4,84$ & $18,90 \pm 15,50$ & $15,97 \pm 14,38$ & $24,02 \pm 18,24$ & \\
\hline$p$ & 0,085 & 0,291 & 0,931 & 0,866 & 0,026 & 0,088 & 0,770 & 0,688 \\
\hline \multicolumn{9}{|l|}{ Marital status } \\
\hline Married & $7,12 \pm 5,20$ & $7,57 \pm 5,73$ & $8,25 \pm 5,69$ & $4,79 \pm 4,74$ & $18,94 \pm 15,48$ & $15,94 \pm 14,13$ & $25,64 \pm 18,43$ & $23,13 \pm 19,02$ \\
\hline Non-married & $6,58 \pm 5,47$ & $6,75 \pm 5,40$ & $7,31 \pm 5,35$ & $4,27 \pm 4,73$ & $16,90 \pm 14,11$ & $14,47 \pm 13,25$ & $21,18 \pm 16,90$ & $19,89 \pm 16,37$ \\
\hline$p^{*}$ & 0,213 & 0,246 & 0,133 & 0,145 & 0,125 & 0,294 & 0,027 & 0,216 \\
\hline \multicolumn{9}{|l|}{ Seniority (year) } \\
\hline$<10$ & $6,80 \pm 5,26$ & $7,26 \pm 5,47$ & $7,30 \pm 5,04$ & $4,04 \pm 4,20$ & $16,48 \pm 12,39$ & $14,47 \pm 11,24$ & $22,69 \pm 15,78$ & $21,35 \pm 16,24$ \\
\hline$\geq 10$ & $7,00 \pm 5,40$ & $7,17 \pm 5,77$ & $8,55 \pm 6,10$ & $5,23 \pm 5,27$ & $20,08 \pm 17,46$ & $16,39 \pm 16,36$ & $25,10 \pm 20,23$ & $22,27 \pm 20,01$ \\
\hline p & 0,741 & 0,895 & 0,056 & 0,033 & 0,041 & 0,236 & 0,252 & 0,665 \\
\hline \multicolumn{9}{|l|}{$\begin{array}{l}\text { Types of } \\
\text { working }\end{array}$} \\
\hline Daytime & $7,97 \pm 5,72$ & $7,87 \pm 5,65$ & $7,52 \pm 5,46$ & $5,34 \pm 6,16$ & $17,63 \pm 14,08$ & $13,17 \pm 11,31$ & $24,50 \pm 16,80$ & $19,04 \pm 15,24$ \\
\hline Shift & $6,64 \pm 5,20$ & $7,07 \pm 5,58$ & $9,34 \pm 5,79$ & $4,39 \pm 4,34$ & $18,17 \pm 15,13$ & $15,80 \pm 14,23$ & $23,59 \pm 18,17$ & $22,38 \pm 18,53$ \\
\hline$p$ & 0,117 & 0,293 & 0,028 & 0,924 & 0,818 & 0,289 & 0,445 & 0,282 \\
\hline \multicolumn{9}{|l|}{ Types of clinic } \\
\hline Internal & $7,08 \pm 5,52$ & $7,27 \pm 5,82$ & $7,80 \pm 5,71$ & $4,29 \pm 4,84$ & $19,12 \pm 16,57$ & $15,86 \pm 14,67$ & $24,18 \pm 18,95$ & $22,02 \pm 18,86$ \\
\hline Surgical & $6,64 \pm 5,06$ & $7,15 \pm 5,31$ & $7,93 \pm 5,38$ & $4,93 \pm 4,59$ & $16,71 \pm 12,39$ & $14,63 \pm 12,50$ & $23,21 \pm 16,51$ & $21,43 \pm 16,86$ \\
\hline$p$ & 0,312 & 0,114 & 0,180 & 0,875 & 0,021 & 0,280 & 0,079 & 0,117 \\
\hline \multicolumn{9}{|l|}{$\begin{array}{l}\text { Chronic } \\
\text { condition }\end{array}$} \\
\hline $\mathrm{Had}$ & $7,94 \pm 5,20$ & $8,52 \pm 5,52$ & $8,85 \pm 6,29$ & $5,54 \pm 5,45$ & $19,21 \pm 15,16$ & $16,12 \pm 14,03$ & $28,08 \pm 22,05$ & $25,82 \pm 21,70$ \\
\hline Had not & $6,53 \pm 5,32$ & $6,78 \pm 5,56$ & $7,52 \pm 5,26$ & $4,24 \pm 4,43$ & $17,69 \pm 14,86$ & $15,05 \pm 13,69$ & $22,29 \pm 16,06$ & $20,39 \pm 16,38$ \\
\hline$p$ & 0,018 & 0,011 & 0,166 & 0,072 & 0,383 & 0,497 & 0,155 & 0,167 \\
\hline \multicolumn{9}{|l|}{ BMI (kg/m2) } \\
\hline$<25$ & $7,09 \pm 5,35$ & $7,28 \pm 5,54$ & $7,52 \pm 5,28$ & $4,35 \pm 4,39$ & $17,60 \pm 14,27$ & $15,41 \pm 13,46$ & $22,83 \pm 17,19$ & $20,77 \pm 17,51$ \\
\hline$\geq 25$ & $6,52 \pm 5,26$ & $7,11 \pm 5,72$ & $8,47 \pm 6,01$ & $4,96 \pm 5,30$ & $18,93 \pm 16,09$ & $15,15 \pm 14,35$ & $25,44 \pm 19,11$ & $23,56 \pm 18,78$ \\
\hline$p$ & 0,279 & 0,622 & 0,278 & 0,614 & 0,766 & 0,520 & 0,303 & 0,148 \\
\hline
\end{tabular}

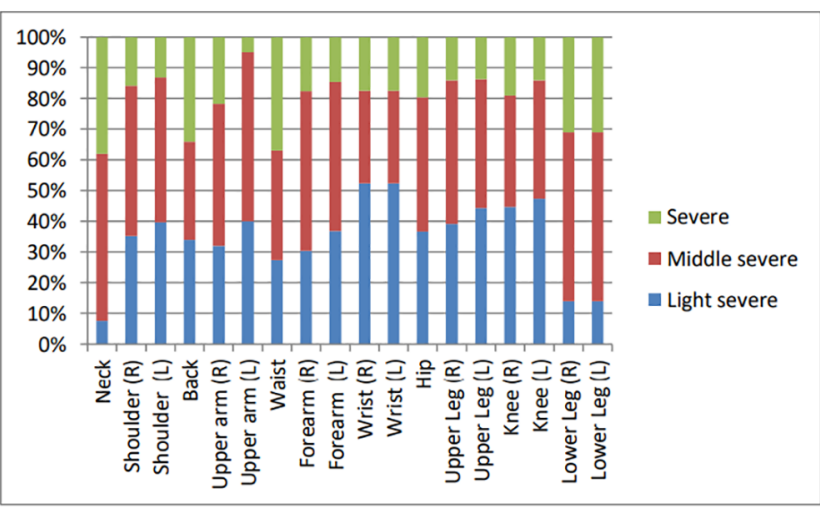

Figure 1. The degree of pain or discomfort according to body areas. study, it was determined that female nurses had significantly higher scores in neck, hips, upper right extremity than male nurses $(p<0.05)$.

Nurses those with university graduates had higher scores in the upper right extremity compared to high school graduates $(p<0.05)$. It was determined that the scores obtained from the lower right extremity were higher than the married people $(p<0.05)$. Married nurses had higher scores in lower right extremity than unmarried $(p<0.05)$. The scores obtained from hip and upper right extremity were higher among nurses those with $\geq 10$ years seniority $(p<0.05)$. The scores obtained from the waist were found to be significantly higher in those with shift working compared to those with daytime working. Nurses with chronic condition had significantly higher scores in neck and back areas than those without chronic condition $(p<0.05)$. 
Table 4. The severity of insomnia according to painful body areas in the participants.

\begin{tabular}{|c|c|c|c|c|c|c|c|c|c|}
\hline \multirow{3}{*}{ Painful body areas } & \multicolumn{9}{|c|}{ Insomnia } \\
\hline & \multicolumn{2}{|c|}{ Insignificant $(\mathrm{n}=89)$} & \multicolumn{2}{|c|}{ Threshold $(n=127)$} & \multicolumn{2}{|c|}{ Middle/severe $(n=77)$} & \multicolumn{2}{|c|}{ Total $(n=293)$} & \multirow[t]{2}{*}{$\chi^{2 / p}$} \\
\hline & No. & $\%$ & No. & $\%$ & No. & $\%$ & No. & $\%$ & \\
\hline Neck & 43 & 21,7 & 88 & 44,5 & 67 & 33,8 & 198 & 67,6 & $21,646 / 0,000$ \\
\hline Shoulder (R) & 36 & 21,7 & 76 & 45,8 & 54 & 32,5 & 166 & 56,7 & $13,671 / 0,000$ \\
\hline Shoulder (L) & 31 & 22,6 & 62 & 45,3 & 44 & 32,1 & 137 & 46,8 & $7,303 / 0,013$ \\
\hline Back & 49 & 24,7 & 94 & 47,5 & 55 & 27,8 & 198 & 67,6 & $9,146 / 0,002$ \\
\hline Upper arm (R) & 22 & 19,1 & 51 & 44,4 & 42 & 36,5 & 115 & 39,2 & $11,318 / 0,000$ \\
\hline Upper arm (L) & 20 & 21,5 & 42 & 45,2 & 31 & 33,3 & 93 & 31,7 & $5,069 / 0,024$ \\
\hline Waist & 53 & 24,8 & 101 & 47,2 & 60 & 28,0 & 214 & 73,0 & $11,807 / 0,003$ \\
\hline Forearm (R) & 17 & 18,3 & 43 & 48,3 & 30 & 33,4 & 90 & 30,7 & $11,250 / 0,004$ \\
\hline Wrist $(\mathrm{R})$ & 20 & 21,5 & 39 & 41,9 & 34 & 36,6 & 93 & 31,7 & $5,069 / 0,024$ \\
\hline Hip & 23 & 19,0 & 64 & 52,9 & 34 & 28,1 & 121 & 41,3 & $12,593 / 0,000$ \\
\hline Upper leg (R) & 32 & 23,4 & 63 & 46,0 & 42 & 30,6 & 137 & 46,8 & $5,992 / 0,014$ \\
\hline
\end{tabular}

Table 5. Multiple logistic regression analysis of painful body areas affecting insomnia.

\begin{tabular}{|c|c|c|c|}
\hline Variables & Adjusted OR & $95 \% \mathrm{CI}$ & $\mathrm{p}$ \\
\hline Neck pain & 1,21 & $1.31-2.45$ & 0.000 \\
\hline Shoulder (R) pain & 1.04 & $1.02-1.98$ & 0,023 \\
\hline Upper $\operatorname{arm}(\mathrm{R})$ pain & 1.12 & $1.06-2.02$ & 0,000 \\
\hline
\end{tabular}

The severity of insomnia according to the body regions were shown in Table 4. It was determined that the threshold level of insomnia was significantly higher in those with MSD except the knee and lower leg region $(p<0.01, p<0.05)$. Multiple binary logistic regression analysis of painful body areas affecting insomnia was given in Table 5. Insomnia was $1.21(\mathrm{aOR}=1.21 ; 95 \%$ $\mathrm{CI}=1.31-2.45 ; p=0.000)$ times higher in those with neck pain, 1.04 $(\mathrm{aOR}=1.04 ; 95 \% \mathrm{CI}=1.02-1.98 ; p=0.023)$ times higher in those with right shoulder pain and $1.12(\mathrm{aOR}=1.12 ; 95 \% \mathrm{CI}=1.06-2.12$; $p=0.000)$ times higher in those with right upper arm pain.

\section{DISCUSSION}

This study was conducted with the considering that MSD were an important job stress among nurses and may affect the severity of insomnia. Nursing profession requires physical difficulties such as weight lifting, improper body posture, and exposure to psychological stress factors. Continuous exposure to these risk factors causes MSD ${ }^{21}$.

In the current study, it was found that the body regions with the most pain complaints were waist $(73 \%)$, neck $(67.6 \%)$, back (67.6\%), and shoulder (right 56.7\%). Also, these regions were obstacle for job performance (Table 2). A study conducted in USA reported that the body areas where the MSD were seen most frequently among the nurses were waist, back, neck, and shoulders ${ }^{22}$. Another study has shown that pain and discomfort were more common in the back region among Jordanian nurses ${ }^{23}$.

Similar to USA and Jordanian studies, in Turkey MSD were shown in waist, back, neck, shoulders, and lower extremity areas among nurses ${ }^{24,25}$. The result obtained from our study was compatible with the results of both national and international studies. Nursing activities are a dynamic process in patient care and treatment. In this process, physical movements may not suitable for the body posture that cause difficulties in the musculoskeletal structure.
Some groups (women, those with higher seniority, shift workers, those with major chronic diseases such as diabetes) were shown to be more prone to MSD among nursing profession ${ }^{26-28}$. Indeed, similar results were found in this study. Female nurses and nurses those with higher educated, married, higher seniority, shift working, working in internal clinics, and chronic diseases were more pain complaints in any body area (Table 3). Frequent occurrence of MSD in female nurses can be affected by the traditional gender roles and physiological processes (pregnancy, birth, etc.).

There is evidence that education is an important risk factor for the formation of MSDs and that highly educated individual's work in better positions in organizations ${ }^{29-32}$. However, in accordance with our study, it was reported that MSDs were more frequent among highly educated nurses ${ }^{33,34}$. Such a result may be due to highly educated nurses had more intense work and responsibilities in clinics.

Marriage brings additional tasks and responsibilities to individual's life. This increased duties and responsibilities may cause nurses to experience more musculoskeletal pain. Also higher seniority in profession can be a pressure on musculoskeletal system and cause pain.

In the present study, the rates of MSDs in different parts of the body were found to be greater in those who had a chronic illness. This is an expected result. It was reported that long working hours cause both physical and psycho-social problems and increase MSDs ${ }^{13,35}$. Work-related MSD not only affect work productivity, but also negatively affect quality of life $\mathrm{f}^{36,37}$. It was stated that pain in the musculoskeletal system impairs sleep patterns ${ }^{38}$. Musculoskeletal pain is a known cause of sleep disturbance ${ }^{39}$. All these evidence supported our findings. In our study, insomnia severity was at the threshold level in all group. The severity of insomnia at the threshold level was found to be significantly higher in nurses with pain complaints in almost all body areas except knee and lower leg region (Table 4). Neck pain, 
right shoulder pain, and right upper arm pain were risk factors for insomnia (Table 5).

\section{CONCLUSION}

In our study, it was determined that MSD were common in the upper body areas and the severity of insomnia was at the threshold level. Neck, right shoulder, and right upper arm were risky body areas for insomnia. All these problems can trigger other physical and mental disorders and reduce job performance. Nurses should be trained on ergonomics and encouraged for exercises to reduce the frequency of musculoskeletal disorders.

\section{REFERENCES}

1. International Labour Organization (ILO). Safety and health at work: a vision for sustainable prevention [Internet]. Frankfurt: ILO; 2014; [access in ANO Mês dia]. Available from: https://www.ilo.org/wcmsp5/ groups/public/---ed_protect/---protrav/---safework/documents/ publication/wcms_301214.pdf

2. Sadeghian F, Hosseinzadeh S, Aliyari R. Do psychological factors increase the risk for low back pain among nurses? A comparing according to crosssectional and prospective analysis. Saf Health Work. 2014 Mar;5(1):13-6. DOI: http://dx.doi.org/10.1016/j.shaw.2013.11.004

3. Smith DR, Leggat PA, Speare R. Musculoskeletal disorders and psychosocial risk factors among veterinarians in Queensland, Australia. Aust Vet J. 2009;87(7):260-5.Costa BR, Vieira ER. Risk factors for work-related musculoskeletal disorders: a systematic review of recent longitudinal studies. Am J Ind Med. 2010 Mar;53(3):285-323.

4. Warnakulasuriya SSP, Peiris-John RJ, Coggon D, Ntani G, Sathiakumar $\mathrm{N}$, Wickremasinghe AR. Musculoskeletal pain in four occupational populations in Sri Lanka. Occup Med (Lond). 2012;62(4):269-72.

5. Chung YC, Hung CT, Li SF, Lee HM, Wang SG, Chang SC, et al. Risk of musculoskeletal disorder among Taiwanese nurses cohort: a nationwide population- based study. BMC Musculoskelet Disord. 2013 Apr;14:144.

6. Ferreira RC, Griep RH, Fonseca MJM, Rotenberg L. A multifactorial approach to sickness absenteeism among nursing staff. Rev Saude Publica. 2012 Apr;46(2):259-68.

7. Reza SK. Prevalence of musculoskeletal disorders among paramedics working in a large hospital in Ahwaz, southwestern Iran in 2010. Int J Occup Env Med [Internet]. 2011 Jul; [cited ANO Mês dia]; 2(3):157-65. Available from: https://theijoem.com/ijoem/index.php/ijoem/article/view/98/191

8. Kee D, Seo SR. Musculoskeletal disorders among nursing personnel in Korea. Int I Ind Ergon. 2007 Mar;37(3):207-12.

9. Souza AC, Alexandre NMC. Musculoskeletal symptoms, work ability, and disability among nursing personnel. Workplace Health Saf. 2012 Aug;60(8):353-60.

10. Roghayeh A, Choobineh A, Hasanzade J. Musculoskeletal load assessment in hospital nurses with patient transfer activity. Int J Occup Hyg. 2013;5(2):39-45.

11. Choobineh A, Rajaeefard A, Neghab M. Association between perceived demands and musculoskeletal disorders among hospital nurses of Shiraz University of Medical Sciences: a questionnaire survey. Int J Occup Saf Ergon. 2006;12(4):409-16.

12. Attar SM. Frequency and risk factors of musculoskeletal pain in nurses at a tertiary centre in Jeddah, Saudi Arabia: a cross sectional study. BMC Res Notes [Internet]. 2014; [cited ANO Mês dia]; 7:61. Available from: http:/ /ovidsp.ovid.com/ovidweb.cgi? $\mathrm{T}=\mathrm{JS} \& \mathrm{PAGE}=$ reference $\& \mathrm{D}=$ emed $12 \& N E W S=\& A N=24460669$

13. Karimian R, Rahnama N, Habibi E, Ghasemi GA, Karimian M. The effect of corrective exercises on musculoskeletal disorders. Health Syst Res Fall [Internet]. 2010; [cited ANO Mês dia]; 6(3):540-8. Available from: https://www.sid.ir/en/journal/ViewPaper.aspx?ID=208552

14. Vinstrup J, Jakobsen MD, Calatayud J, Jay K, Andersen LL. Association of stress and musculoskeletal pain with poor sleep: cross-sectional study among 3,600 hospital workers. Front Neurol. 2018 Nov;9:968.

15. Akınc1 E, Orhan F. Circadian rhythm sleep disorders. Curr Appr Psychiatr. 2016;8(2):178-89. DOI: https://doi.org/10.18863/pgy.81775

16. Hedge A, Morimoto S, McCrobie D. Effects of keyboard tray geometry on upper body posture and comfort. Ergonomics. 1999 Oct;42(10):1333-49.
17. Erdinc O, Hot K, Ozkaya M. Turkish version of the Cornell musculoskeletal discomfort questionnaire: cross-cultural adaptation and validation. Work. 2011;39(3):251-60.

18. Bastien $\mathrm{CH}$, Vallières A, Morin CM. Validation of the insomnia severity index as an outcome measure for insomnia research. Sleep Med. 2001 Jul;2(4):297-307.

19. Boysan M, Güleç M, Beşiroğlu L. Psychometric properties of the insomnia severity index in Turkish sample. Anatol J Psychiatry. 2010;11:248-52.

20. Bernal D, Campos-Serna J, Tobias A, Vargas-Prada S, Benavides FG, Serra C. Work- related psychosocial risk factors and musculoskeletal disorders in hospital nurses and nursing aides: a systematic review and meta-analysis. Int J Nurs Stud. 2015 Feb;52(2):635-48. DOI: http:// dx.doi.org/10.1016/j.ijnurstu.2014.11.003

21. Daraiseh NM, Cronin SN, Davis LS, Shell RL, Karwowski W. Low back symptoms among hospital nurses, associations to individual factors and pain in multiple body regions. Int J Ind Ergon. 2010 Jan;40(1):19-24. DOI: http://dx.doi.org/10.1016/j.ergon.2009.11.004

22. Shawashi TO, Subih MM, Al Hadid LAR, Abu Adas M. Occupationalrelated back pain among Jordanian nurses: a descriptive study. Int J Nurs Pract. 2015 May;21(Suppl 2):108-14.

23. Gül A, Üstündağ H, Kahraman B, Purisa S. Evaluation of musculoskeletal pain among nurses. Arch Health Sci Res. 2014;1(1):1-10.

24. Soylar P, Ozer A. Evaluation of the prevalence of musculoskeletal disorders in nurses: a systematic review. Med Sci Int Med J. 2018 Sep;7(3):479-85.

25. Raeisi S, Hosseini M, Attarchi MS, Golabadi M, Rezaei MS, Namvar M. The association between job type and ward of service of nursing personnel and prevalence of musculoskeletal disorders. Razi J Med Sci. 2013 Jun;20(108):1-10.

26. Yilmaz E, Özkan S. Determination of the prevalence of low back pain among nurses working in hospitals. Turk J Phys Med Rehab. 2008;54(1):8-12.

27. Barrau-Baumstarck K, Rebeschini E, Dalivoust G, Durand-Bruguerolle D, Gazazian G, Martin F. Effets du type d'aménagement horaire du travail sur la qualité de vie: étude auprès de 145 agents paramédicaux des services de réanimation. Presse Med. 2009;38(3):346-53.

28. Brandt M, Sundstrup E, Jakobsen MD, Jay K, Colado JC, Wang Y, et al. Association between neck/shoulder pain and trapezius muscle tenderness in office workers. Pain Res Treat. 2014;2014:352735.

29. Wu S, He L, Li J, Wang J, Wang S. Visual display terminal use increases the prevalence and risk of work-related musculoskeletal disorders among Chinese office workers: a cross-sectional study. J Occup Health. 2012;54(1):34-43.

30. Baek JH, Kim YS, Yi KH. Relationship between comorbid health problems and musculoskeletal disorders resulting in musculoskeletal complaints and musculoskeletal sickness absence among employees in Korea. Saf Health Work. 2015 Jun;6(2):128-33. DOI: http://dx.doi. org/10.1016/j.shaw.2015.03.002

31. Madadizadeh F, Vali L, Rafiei S, Akbarnejad Z. Risk factors associated with musculoskeletal disorders of the neck and shoulder in the personnel of Kerman University of Medical Sciences. Electron Physician. 2017 May;9(5):4341-8.

32. Sezgin D, Esin MN. Predisposing factors for musculoskeletal symptoms in intensive care unit nurses. Int Nurs Rev. 2015 Mar;62(1):92-101.

33. Kalkim A, Midilli T, Dogru S. Musculoskeletal disorder symptoms in nurses and etiological factors: a cross-sectional research. Ann Med Res. 2019;26(3):374.

34. Bae SH, Fabry D. Assessing the relationships between nurse work hours/overtime and nurse and patient outcomes: systematic literature review. Nurs Outlook. 2014 Mar;62(2):138-56. DOI: http://dx.doi. org/10.1016/j.outlook.2013.10.009

35. Hagberg M, Violante FS, Bonfiglioli R, Descatha A, Gold J, Evanoff B, et al. Prevention of musculoskeletal disorders in workers: classification and health surveillance - Statements of the Scientific Committee on Musculoskeletal Disorders of the International Commission on Occupational Health. BMC Musculoskelet Disord. 2012 Jun;13:109.

36. Mehralizadeh S, Dehdashti A, Kashani MM. Structural equation model of interactions between risk factors and work-related musculoskeletal complaints among Iranian hospital nurses. Work. 2017;57(1):137-46.

37. Artner J, Cakir B, Spiekermann JA, Kurz S, Leucht F, Reichel H, et al. Prevalence of sleep deprivation in patients with chronic neck and back pain: a retrospective evaluation of 1016 patients. J Pain Res [Internet]. 2012 Dec; [cited ANO Mês dia]; 2013:1-6. Available from: https:// www.dovepress.com/prevalence-of-sleep-deprivation-in-patients-withchronic-neck-and-back-peer-reviewed-article-JPR

38. Zhang Y, Duffy JF, Castillero ER, Wang K. Chronotype, sleep characteristics, and musculoskeletal disorders among hospital nurses. Workplace Health Saf. 2018 Jan;66(1):8-15. 